\title{
INSTRUMENTAL ANALOGY
}

\author{
GAVIN PERIN \\ Faculty of Design, Architecture and Building \\ University of Technology, Sydney \\ PO Box 123, Broadway, NSW 2007, Australia \\ Gavin.perin@uts.edu.au
}

\begin{abstract}
The scalar mediation of the object through the space of representation ensures design methodologies based on similitude or procedural techniques must initially work upon appropriated forms. Given that translation ensures that these forms remain as a trace the architectural object is implicitly reliant on the application of analogy. While still bound to the act of drawing in, on or through the digital distinguishes itself from the explicit appropriation of forms and techniques typical of pre-digital design methodologies because analogy is more than re-presention.

The interaction of data mining and modelling software to act on qualitative and quantitative data sets offers a different design process because it allows analogy to operate as a primary disciplinary condition. Importantly the tension between the analogy, software and data enables a productive play that doesn't immediately prescribe or defer to conventional architectural forms. No longer concerned with re-presentation, analogy is subsequently free to explore and test architectural objects where the 'content' or value resides in the affect of form and therefore undoing the longstanding binary logic separating form and content.
\end{abstract}

The paper, in reference to specific projects, will discuss the capacity of analogous modes and techniques in translating data into form through modelling software. An argument will be made that the value of this line of design-based research resides in the unique way in which its propositional and procedural opportunities calls into issue the notion of affect.

Keywords: Analogy, Affect, Data, Information.

\section{Instrumental Analogy.}

Despite the last decade of digitally authored design processes there remains a divide, equally in the academy and the profession, about the intrinsic value of the artefacts arising from these methodologies. The tendency to promote such artefacts as avant-garde, when coupled with a distinctive visual language, no doubt antagonises those who see the instrumentality of these digital tools as diminishing architecture's own specific historic, theoretic and tectonic frameworks. These attacks might be rejected as nothing more than a trace of architectural iconophobia if it weren't for the willingness for digital practitioners to exploit the imagistic facility of these tools. This tactic becomes particularly problematic when the image is asked to establish the value of such forms, instigating a process where these artefacts are propagandised precisely on the demonstration of formal uniqueness. Accordingly for the digital is to possess any worth it is equally incumbent on all parties to move beyond the image and focus instead on the formal implications of the techniques drawing rather than the drawing itself. This worth lies not only in the capacity of the digital to foreground contingent information and data sets but also in the way in which it offers a proliferation in the 
analogous frameworks that avail themselves in the thinking and making of architecture. These distinctive analogous frameworks offer propositional and procedural opportunities that, once liberated from the concern with the drawing, enable an exploration of broader social issues within notions of performance and affect. Such a position relies on the acceptance that re-conceptualisation of representation from formal similitude to formally generative tool ensures that design instigates an interplay with the act of drawing between disciplinary knowledge and the modes and tools of representation.

Robin Evans (153-193) argues that the tools and modes of representation significantly mediate form because of the scalar process of ideation to realisation. The mediation of architecture by the techniques of drawing suggests a more radical approach where representational space can be deliberately exploited as the primary mechanism to explore and test form. This is in stark contrast to traditional design processes where such an intercession is conceptually problematic because it severs formal and material fidelity. The drawing must communicate, not mediate, form. To rupture the tectonic basis of form making is therefore to contaminate the design process itself. The belief that the integrity of the artefact is established by its link to the 'real' constrains form making to the discipline to precedent, whether it is based on formal or structural and constructional logics. Precedent, as a model that offers a "standard or example for imitation or comparison" (The Macquarie Dictionary 72), can only ever be understood as partial similarity and is only evident as a trace within each 'new' project. The use of precedent is to treat form as analogous to those exemplars and models because each new architectural project requires a unique response. Andrew Benjamin's (11) use of the term 'alterity', is particularly helpful here in that the identification of the uniqueness of each new architectural artefact is a product of the contingency of the re-visiting of the issue of function over time. Each revisiting of function must be premised on the expectation of difference. The dictates of function together with the contingencies of the temporal interpretation of program and the specificities of site ensures that each iteration of form instigates a process of reconfiguration of these factors that renders every project unique. Accordingly privileging precedent as a template or exemplar renders it analogous to the model on which it is drawn. The model, of course, can only act as a formal guide, so that processes wedded to precedent are rendered analogous on the basis that analogy, as a "correspondence between the relations of things to one another" (The Macquarie Dictionary 1381) or "a partial similarity in particular circumstances on which a comparison can be based" (The Macquarie Dictionary 1381), functions as a product of dissimilarity between projects within the discipline rather than a categorical disciplinary similarity of which it can be said to be a part of. Accordingly the dissimilarity within the discipline, rather than outside or between disciplines, renders precedent based design processes as a function of analogy.

The presence of analogy is not surprising given that the scalar mediation of the artefact through the space of representation ensures that all design methodologies, whether they are based on similitude or procedural techniques, must initially work upon a selection of form (Evans 156). It would be naïve to suggest that digital design practice is the first example of design processes that are able to conceive of design methods that act outside specific disciplinary knowledge. There are numerous examples over the last twenty years alone where methods have been actively developed to dislodge precedent. The important distinction between the digital and these other processes is that they tend to function via a deliberate interdisciplinary slippage by appropriating modes of practice from other fields. These processes have been validated through demonstrating the architectural-ness of the artefact rather than the architectural-ness of the process itself. While still bound to the act of drawing in, on or through, the digital distinguishes itself from the explicit interdisciplinary appropriation of forms and techniques because analogy is more than a deliberate attempt to free oneself from the conventional.

Practitioners of digital design practice may appropriate tools outside the discipline but they do so for their capacity to translate information relevant to architecture. The exploitation of the instrumentality of the digital tools of representation are, as such, conceived to work within the discipline but outside a reliance on the reapplication of precedent form. The question of form is related to the capacity of the digital to capture and simulate the contingent and temporal through the parametric exploitation of software. For Greg Lynn this allows architects to conceptually approach architecture through inter-relational flux rather than stable form, where the "shape of statistics, or parameters, may yield a culturally symbolic form, yet at the beginning, their role is more inchoate" (39). However, while it is clear that use of parameters and statistics requires an abstract, and often less representational origin for design, this in no way frees such processes from analogy. The digital might be an artificial rather than organic process but this understanding is belied when Lynn describes such processes as natural and evolutionary. To quote Lynn, animation processes "implies the evolution of a form and its shaping of forces; it suggests animalism, animism, growth, actualisation, vitality and virtuality" (39). This may be pedantic, but clearly the attempt to establish legitimacy for the process requires, in this case, the erasure the any indication that the process is analogous. This is particularly evident when Lynn seamlessly shifts the use of the spline from its original role as a geometric method of indexing the effects of gravity on material to an indexing of data. One might tolerate the making of form based on the correspondence to structural performance; however, once this link is ruptured it is clear that analogy is again at work because the spline represents or stands in for information. 
The fact that these processes are analogous should not, of course, be of any surprise given that information is immaterial. However, claims that these models transform information cleanly indicate a certain level of criticality. This is not to argue that fidelity between information and form is impossible. NOX's wet grid projects offer a prime example of how the artefact is formed within a strict understanding of analogous performance. This system, either as a way of distributing circulation (Soft Office and ParisBrain projects) or structure (World Trade Centre project) is able to set up an assessment of performance that is directly embedded within an understanding of the interplay of gravity and material. Yet in as much as the analogue computer is not concerned with the actual materiality of the project, the folding of the adopted material system back into a tectonic expression is still a highly interpretive act. To see the outcome of any wet grid as purely a tectonic question is to erase the potentiality of the drawing in a similar same way as when one draws a section of concrete footing as a perfect rectangle. Aligning the mode of representation to a built condition is to somehow enforce a formal discipline on the way one sees the artefact and so limits the offered interpretative opportunities. Nor is there any questioning of either the data's status or actual worth. The privileging of quantitative information fundamentally possesses the danger of the reduction of complexity to statistical averaging, which serves only to promote the normative over the particular. The potential of the digital to generate a range of options is underscored by an acknowledgment that the digital design process can never be automatic and lineal.

If such practices rely on analogy as much as any other, more conventional, practices then the Digital's contribution to design based research exists beyond establishing legitimacy through fidelity to data. Architecture still departs from the selection and then application of form, and the translation of data can occur only once analogous form has been selected. The important difference is that the analogous forms of the digital function as a performative mechanism rather than some type of formal template. As with all technological shifts the disruption caused by theses new methods of formal production offers another scopic regime through which to make and understand the artefact. This, in turn, alters the visual and social understanding of the form. As Martin Jay points out, any consideration of the validity of a particular scopic regime requires us to first "learn to see the virtues of differentiated ocular experiences (and) wean ourselves from the fiction of a "true" vision and revel instead in the possibilities opened up by the scopic regimes we have already invented and the one's... that are doubtless to come." (20). The digital is obviously not natural but to reject its validity would be to implicitly suggest another regime is.

The digital fundamentally reconfigures the way in which form making is thought because the tools and techniques allow us not to erase but instead build on existing analogous modes. The new scopic regime of the digital should be approached then with a certain level of optimistic inquiry. To quote Jay again, what is required is a clear acknowledgment of "the plurality of the scopic regimes now available to us. Rather than demonize one or another, it may be less dangerous to explore the implications, both positive and negative, of each." (20). The significant and distinguishing attribute of the digital evidently lies in its ability to facilitate analogous design practices that approach formal and spatial issues from a point of complexity rather than either formal appropriation, simplicity or clarity. Simultaneously the generative capacity of digital tools forces a mode of engagement where formal instrumentality requires an open exploitation of an alternative scopic regime centred at the site of architecture's real space of work, the drawing. The validity of this line of inquiry is not that it is new but rather than it allows us to re-think and re-interrogate the question of form making. The corresponding recalibration in the hierarchy of representational modes from orthographic projection and perspective to the diagram not only fundamentally re-prioritises the working order in which modes the architect deploys them but in fact expands the repertoire of drawing practice. In this light the various ways of thinking about form, be they ecological systems, the animation of temporal variation or scripting, allow the designer to re-conceptualise the techniques of form making, but also, more importantly, offers alternative ways in which to engage with the social and cultural questions.

If the digital requires an interpretative approach to both the initial selection of form and an anticipation of its performance under the affect of information then it seems reasonable to suggest that the issue of signification might also be factored into the project and not outside the architect's remit. The cultural significance of any artefact is perhaps too important to leave as a retrospective act. One may or may not agree with the prevalence of the image but for architecture, as a social act, it remains an important design issue. This much is clear in P.T.W's use of the bubble analogy for a memorial to the victims of the Indian Ocean Tsunami disaster. The desire to exploit technique fails to register its figural reading within a specific social and cultural context. It is important that architects reclaim a certain level of responsibility for the objects performance both to quantitative data and qualitative cultural information.

It is respect to these issues that l'd like to discuss AARN's scheme for the recent Canberra Parklands Competition, which was for the redesign of a site located on the northeast shore of Lake Burley Griffin at the base of the Parliamentary Triangle. Obviously, as with any truly collective work the trajectories of any specific project can be taken in a number of ways. Personally the initial response to the competition brief developed from the insistence that the design build upon the Griffin Legacy. The desire of the authorities to promote the city through the genius of Griffin is troubling on two counts; first being that Canberra was a 
product of a single hand, and the second that the city today is somehow a true reflection of that plan. Of course, given that the programmatic organization of the Griffins' scheme bears little resemblance to the present city, it is obvious that this plan has been assigned enormous cultural status. The only real remnants of Griffins' legacy lie in the road layout and the dominant landscape. The hexagonal geometry underpinning the city's organizational logic exists in the aerial view only; experientially the equilateral triangle dominants. The geometric configuration of the Parliamentary Triangle effectively folds the imagistic city emblem together with the logic of the plan's spatial organization. Consequently the decision to respond to this figure seemed relevant because of its assigned cultural significance. However, unlike the Griffin's pure geometric form it was always intended that the computer would lead to a formal and spatial complexity, where form was expected to produce a highly complex triangulated tessellated terra-form that not only resisted the symbolic assignation of the equilateral triangle but also provided a formal logic of variation by which to develop and distribute program. The figure of the triangle was, therefore, a tactical response to the issue of the city's motif that could be then formally redeployed as a rationalisation of curvilinear surfaces that reminds one that there is nothing natural about Canberra's landscape.

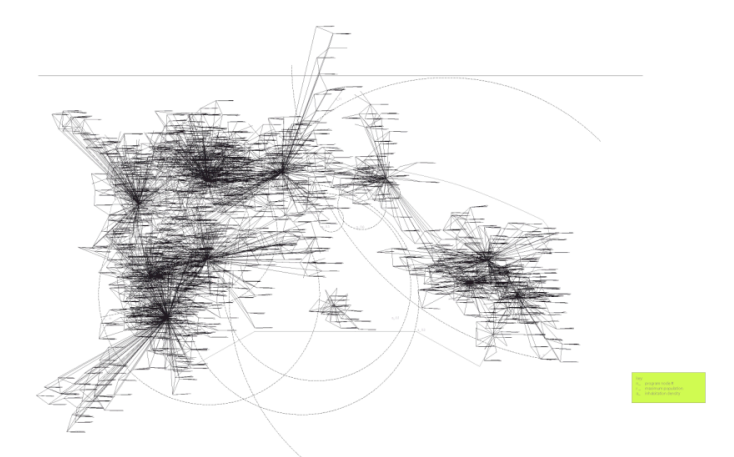

Figure 1. CAARN

At this point the triangle acted as a formal guide without defining a tectonic condition. The approach to the formal articulation at the scale of the site required another analogous form. It was decided that $a$ Maya $\subset$ $L$ Script provided a suitable analogous framework in which to approach the issue of site as an idea of formal distribution (Figure 1). The benefit of the script being that it furnished a skeletal frame that yielded complex tessellated form (Figure 2). The value in adopting this mathematically based script was that the variation in branching angle and length provided a useful analogy for the type of parametric performance the team was after. This performance was further enhanced by defining of a series of zones that, by embedding the effects a range of existing and projected conditions, modified the distribution of this frame. This ensured that the role of analogy was different to those of precedent by delaying form making until the potential of distribution could be assessed. 


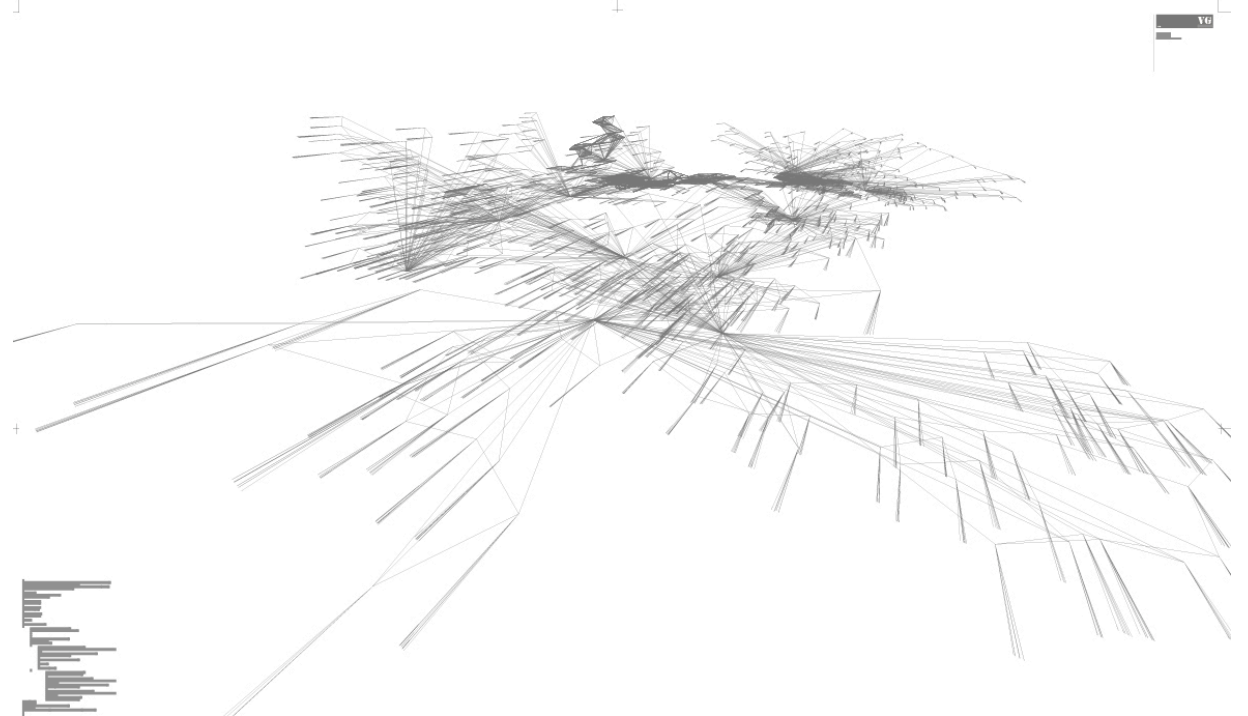

Figure 2 OAARN

The conversion of the $L$ script frame into a complex tessellated landscape, accomplished by a lofting procedure, finally delivers a triangulated form that experientially reinforces the artificiality of landscape (Figure 3). Importantly the approach to program is opportunistic in that the growth of the script suggested that these triangular territories resist the notion of park as a purely recreational space. It effectively allowed the team to think of this landscape as a productive laboratory where the main program, a Museum Of Ecological Succession, sets in motion a gradual temporal reconfiguring of the ground. Therefore it can be said that the selection of the triangle and the script provided analogous forms that together produced a way of thinking about formal and programmatic distribution as a set of performative permutations rather than identifiable built form.

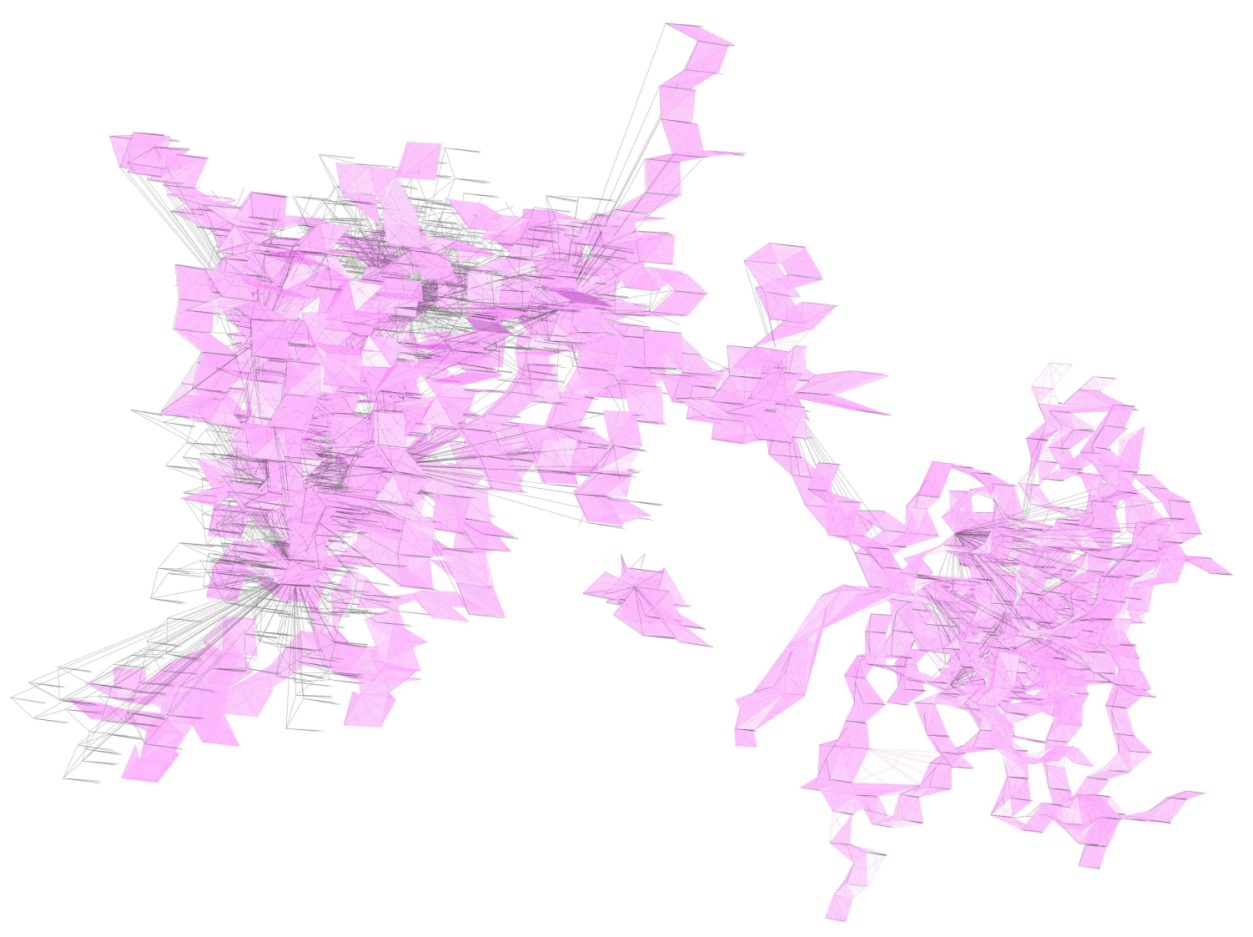

Figure 3 @AARN 
The L-script could have been formally interpreted in numerous ways; at certain moments it was tested as a point force modifying the landscape or through aligning visual density to programmatic density (Figure 4) However, the value of the triangulated terra forming process was that it acted first to question the account of Canberra's development as merely the unfolding of the Griffin's master plan and second remind one that the Canberra's landscape is anything but natural given that it is underpinned by a pervasive geometric order. The E.M.S. presents another triangulated geometry that disrupts the city's overarching geometric order, which as a motif acts as a figure without figurative content and returns to enforce an abeyance of signification to the point that its experiential affect assumes primacy. Working to constantly undo the expectation of order offered by pure geometries the experiential affect of form replaces the figure's narrative effect enabling an engagement with questions of signification and meaning without the usual stability expected of a semiotic clarity. While this situates the outcome within a linguistic framework through the provision of emblematic form it is also rendered instrumental when accepting both that the undoing of cultural signification and that the analogous forms allowed another way of conceiving of the landscape operate at a performative level.

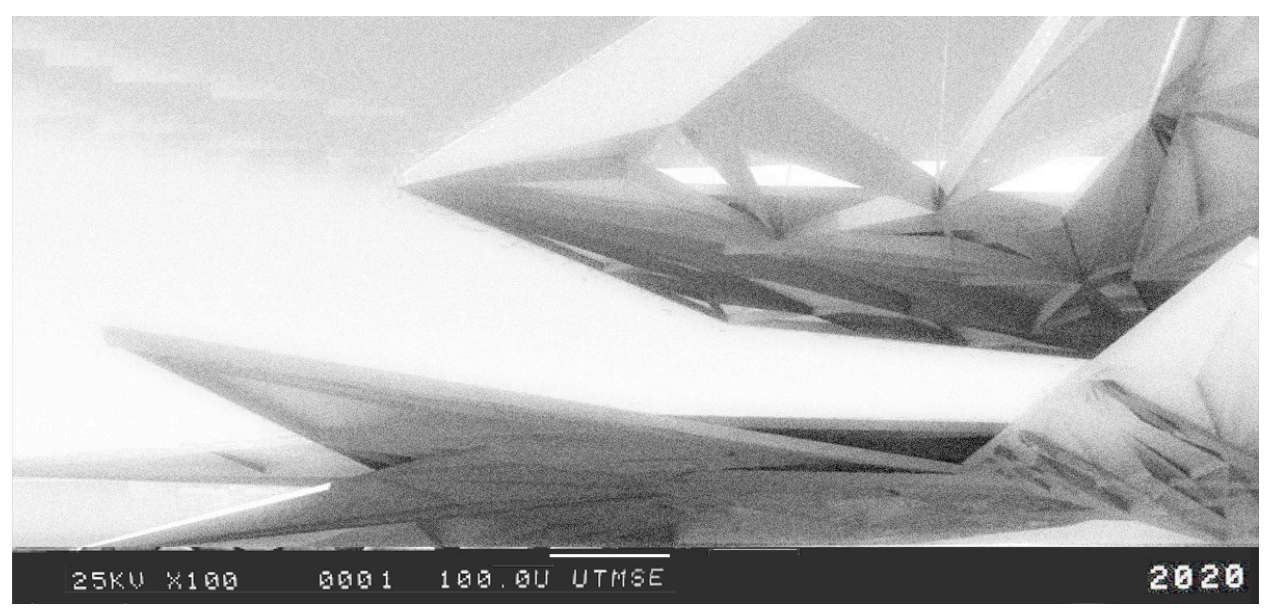

Figure 4 @AARN

The E.M.S. demonstrates that a strategic cultural and performative engagement of the digital's techniques and tools circumvents the issue of novelty. In so doing the digital endgame of formal dexterity is repositioned within a question of the way it performs. The Canberra Parklands project is by no means the solution to questions facing the digital but as its techniques become normalised it does indicate another way in which it might establish a conversation about the potential in understanding the content in form. No longer concerned with re-presentation, analogy is subsequently free to explore and test architectural objects where the 'content' or value resides in the affect of form and therefore undoing the longstanding binary logic separating form and content. The interaction of data and modelling software to act on qualitative and quantitative data sets offers a different design process because it allows analogy to operate as a primary disciplinary condition. Importantly the tension between the analogy, software and data enables a productive play that doesn't immediately prescribe or defer to conventional architectural forms.

\section{References}

Benjamin, A, "Chapter 1, Time, Function and Alterity", Architecture Architectural Philosophy: Repetition, Function, Alterity, , New Brunswick: Athlone Press, 2000, p.11.

Evan's, R., Translations from Drawing to Building and Other Essays, Cambridge, Mass. : MIT Press, 1997, p.153-193.

Evan's, R., Translations from Drawing to Building and Other Essays, Cambridge, Mass. : MIT Press, 1997, p.156.

Lynn, G., Animate Form, New York: Princeton Architectural Press, 1999, p.39.

Lynn, G., Animate Form, New York: Princeton Architectural Press, 1999, p.39.

Jay, M, "Scopic Regimes of Modernity", Vision and Visuality, edited by Hal Foster, New York, N.Y. :New Press (1999), p.20.

Jay, M, "Scopic Regimes of Modernity", Vision and Visuality, edited by Hal Foster, New York, N.Y. :New Press (1999), p.20. 